\title{
Numerical Assignment of Shapes and Symmetries of Borane Molecules and lons
}

\author{
ENOS M.R. KIREMIRE*, LIKIUS S. DANIEL and PHILIPUSHISHIMONE \\ Department of Chemistry and Biochemistry, University of Namibia, \\ Private Bag 13301, Windhoek, Namibia. \\ http://dx.doi.org/10.13005/ojc/300302
}

(Received: June 06, 2014; Accepted: August 06, 2014)

\begin{abstract}
The borane chemistry has continued to expand since the beginning of the twentieth century. It has deeply penetrated into the other fields such as organic chemistry, inorganic chemistry, organometallic chemistry, catalysis, and medicinal fields. Yet some of the average chemists or chemists at an undergraduate or even postgraduate levels find it a challenge to explain the structures of simple boranes. In this article, we present an empirical formula that can be utilized to deduce geometrical shapes of simplesboranes. The formula is so versatile as to be applied to deduce the Lewis structures of simple molecules and ions, inorganic clusters of main group elements, the carbonyl clusters of transition metal complexes as well as carboranes symmetries and hydrocarbons. In the case of hydrocarbons, it is useful in generating isomers of a given hydrocarbon. It is hoped that the formula will be extended to explain the structures or shapes and symmetries of large clusters and to systems which may not obey the octet or eighteen electron rule.
\end{abstract}

Key words: Borane molecules, Emperical formula, Chemists, Electrol rule.

\section{INTRODUCTION}

Borane molecules and ions have fastinated scientists for a long time since the beginning of $20^{\text {th }}$ century ${ }^{1-2}$. Unlike hydrocarbons, boranes do not occur in nature, that is, they are generated synthetically ${ }^{3}$. As it is well known that hydrocarbons are vitally important as they play a crucial role in the provision of energy and many industrial and pharmaceutical chemicals and materials ${ }^{4}$. It is not surprising that boranes have undergone intense investigations for possible utilization in the production of energy as well as in the potential medicalapplications ${ }^{4-6}$. Furthermore, the chemistry of boranes has expanded into other fields of chemistry such as organic and organometallic chemistry ${ }^{7}$. The synthetic techniques developed, bonding as well as shapes and symmetries of neutral boranes and borane ions have challenged great chemists and continue to do so ${ }^{8-15}$.

It is interesting to note that the elements of the periodic table follow an arithmetical progression. This progression may be presented by a simple formula below. 


$$
Z=a_{1}+(n-1) d
$$

where $\mathbf{Z}=$ atomic number of an element in the periodic table, $a_{1}=1$, the first element $(H), d$ $=1$; the difference between successive elements and $\mathrm{n}$ is the $\mathrm{n}^{\text {th }}$ element.

The range of periodic table elements has considerably been expanded with the production of synthetic elements ranging from $Z=99$ to the current 118 element. From 2000 to 2010 , five artificial elements were discovered ( $Z=113,115,116,117$ and 118).

In this paper, we present the assignment of numbers to shapes and symmetries of molecules and ions of boranes. This procedure has been presented earlier ${ }^{16-17}$. However, in this article the empirical formula has been refined to probe detailed linkages including those of the hydrogen atom linkages of the boranes. The numbers are generated from an Empirical Formula given by

$$
k=1 / 2(E-V)
$$

$\mathrm{k}=$ is a representative number ofbonds, linkages or shape and symmetry of a given molecular formula of neutral borane, ion or carborane; $E=$ the sum of octet (8) electrons for the atoms assumed to obey the octet rule in the molecular formula.; $V=$ the sum of the valence electrons of all the atoms in the molecule or cluster.

The empirical formula is readily applicable to transition metal carbonyl complexes with metal- metal bonds and main group clusters which obey 18 and 8 electron rules respectively[ ]. In the case of $\mathrm{H}$ atom in a covalent bonding obeys the 2 electron rule. When the 2, 8 and 18 electron rules when closely scrutinized, it is discerned that these rules have their foundations in the noble gas configurations. In the case of boranes and hydrocarbons to be discussed in another paper, the empirical formula has been refined to include not only the skeletal or linkages but all number the bonds within the formula of the molecule or ion. In view of the rapid expansion of the borane chemistry including potential application, it is important to find a simple method of deducing the structures of boranes at least the simple ones so that they are reasonably explicable at an average or junior chemist. This empirical formula is an attempt in that direction.

\section{Simple examples for illustration}

Let us consider simple molecules and ions first.

Take the case of $\mathrm{C}_{2}$ molecule. When the empirical formula is applied, we find that it has a quadruple bond rather than a double bond as predicted by molecular orbital theory. According to the formula, $k=1 / 2(E-V)$, each of the $C$ atom will obey the octet rule hence $E=2 \times 8=16$, and the sum of valence electrons $\mathrm{V}=2 \times 4=8$. Hence $\mathrm{k}=1 / 2(16-8)$ $=4$. This result is quite interesting in the sense that recently, a quadruple bond for $\mathrm{C}_{2}$ has been found [ ]. For $\mathrm{NO}^{+}$ion, $\mathrm{E}=16, \mathrm{~V}=5+6-1=10$. Hence $\mathrm{k}=3$. Similarly, $\mathrm{CN}^{-}(\mathrm{k}=3)$, $\mathrm{NO}^{-}(\mathrm{k}=2), \mathrm{CO}_{2}(\mathrm{k}=4), \mathrm{HCN}($ $\mathrm{E}=2+8 \times 2=18, \mathrm{~V}=1+4+5=10$ and $\mathrm{k}=4), \mathrm{N}_{2} \mathrm{H}_{4}(\mathrm{E}$ $=4 \times 2+2 \times 8=24, \mathrm{~V}=5 \times 2+4=14$ and $\mathrm{k}=5$ ) and $\mathrm{CH}_{4}$ $(E=8+4 \times 2=16, V=4+4=8$ and $k=4)$. The distribution of bonds of $k$ values such the atoms obey the 2 or 8 electron rule as the case may be for selected molecules/ions is illustrated in the sketch 1 below consistent with the known shapes.

\section{$\mathrm{As}_{4}$ cluster}

Arsenic has five valence electrons and if each is surrounded by 8 electrons, then $E=4 \times 8$ $=32$, and $V=5 \times 4=20$. Hence, $k=1 / 2(32-20)=6$. This means the four atoms are connected by 6 linkages.

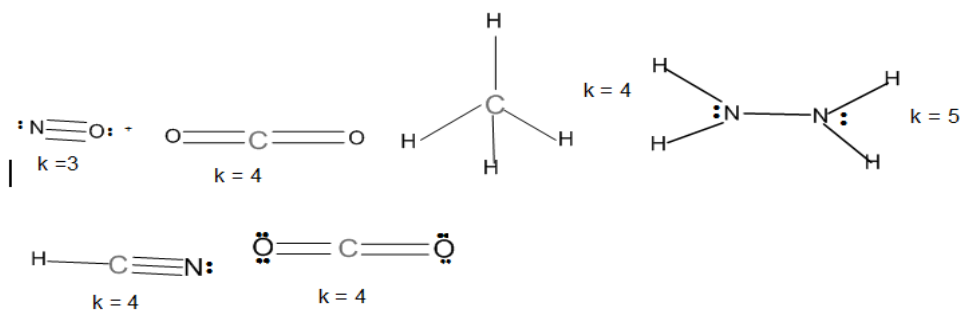

\section{Sketch 1}


This is consistent with a tetrahedral geometry, $T_{d}$ (Fig. 1).

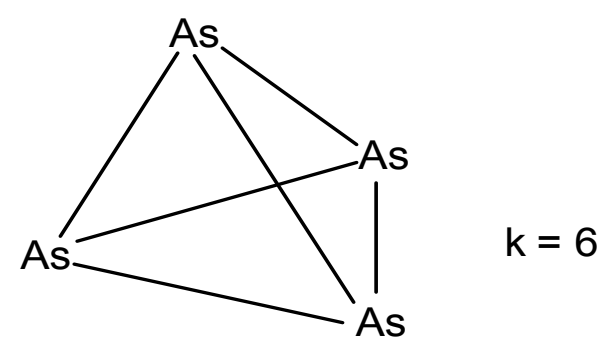

Fig. 1:

Applying the empirical formula $\mathrm{k}=1 / 2(\mathrm{E}-\mathrm{V})$ to the $\mathrm{B}_{2} \mathrm{H}_{6}$ molecule for the two $\mathrm{B}$ atoms excluding the $\mathrm{H}$ atoms,

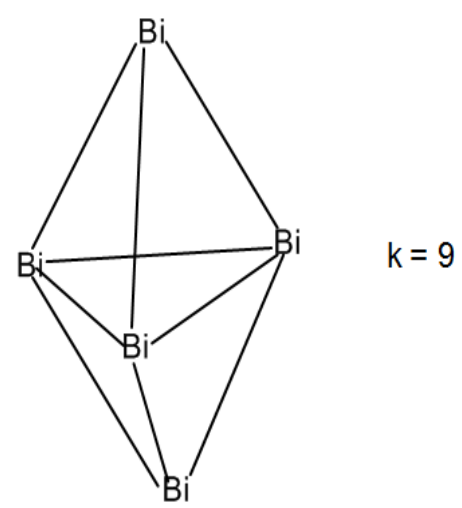

Fig. 2:

$E_{1}=2 \times 8=16, V=2 \times 3+6 \times 1=12$. Hence $k_{1}$ $=1 / 2(16-12)=2$. In principle, the two boron atoms in $\mathrm{B}_{2} \mathrm{H}_{6}$ will linked by a double bond as in $\mathrm{C}_{2} \mathrm{H}_{4}$. The skeletal bonds are indicated in Fig. 4. In order for the boron atoms to obey the octet rule, each $B$ atom must have two additional bonds or linkages for 4 hydrogen atoms. But in order to comply with the octet rule

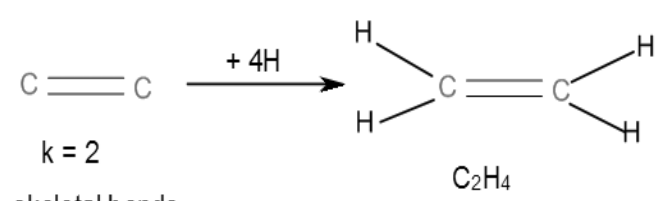

Fig. 3:

$\mathrm{Bi}_{5}{ }^{3+}$ cluster

In this case, the parameters of the empirical formula have the values $E=5 \times 8=40, V=5 \times 5-3=22$ and $k$ $=9$. The 9 linkages are consistent with a trigonal bipyramid geometry $\left(D_{3 h}\right)$.

\section{$\mathrm{C}_{2} \mathrm{H}_{4}$ molecule}

In the case of $\mathrm{C}_{2} \mathrm{H}_{4}$, each of the two $\mathrm{C}$ atoms obeys the octet rule. The skeletal bonds linking up the two atoms are given by $k_{1}=1 / 2(16-12)=2$. If the $\mathrm{H}$ atoms are taken into account, and that each $\mathrm{H}$ atom obeys the 2 electron rule, then the total linkages(bonds) are given by $\mathrm{k}_{2}=1 / 2\left(\mathrm{E}_{2}-\mathrm{V}\right) ; \mathrm{E}_{2}=$ $2 \times 8+4 \times 2=24, V=12$. Hence, $k_{2}=1 / 2(24-12)=6$. Since $k_{1}=2$, then $k_{2}-k_{1}=4$. The 4 linkages will be for the 4 hydrogen atoms to the carbon atoms.

$\mathrm{k}_{2}=6$

$\mathrm{k}_{2}=6$ means that all the 6 bonds linking up the 6 planar atoms in $\mathrm{C}_{2} \mathrm{H}_{4}$ are identified by the $\mathrm{k}_{2}$ value.

\section{$\mathrm{B}_{2} \mathrm{H}_{6}$ molecule}

The bonding and structure of diborane became very controversial when the interest in the borane compounds was ignited by A. Stock who opened the door into the fertile field and many others followed [ ]. The shape of $\mathrm{B}_{2} \mathrm{H}_{6}$ was confirmed to be a doubly bridged one almost similar to that of $\mathrm{C}_{2} \mathrm{H}_{4}$ except that the bridges referred to as banana bonds were perpendicular to the plane of $\mathrm{B}_{2} \mathrm{H}_{4}$ fragment.

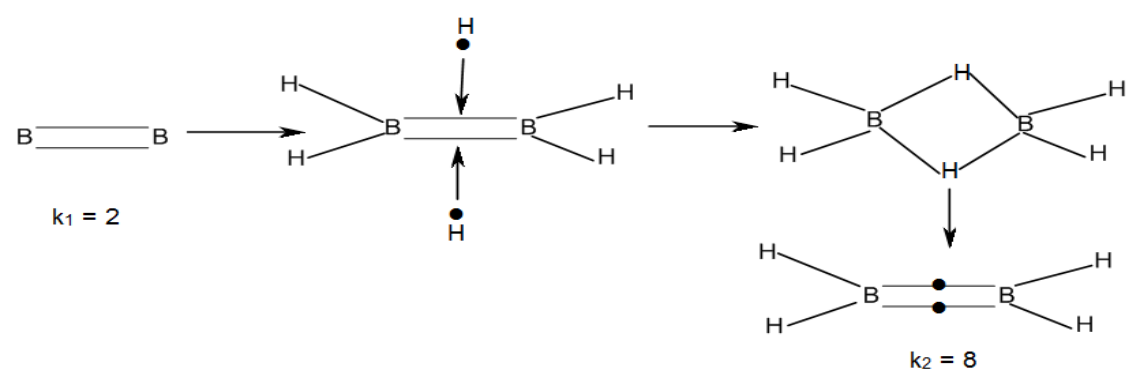

Fig. 4: 
requirement, the 2 additional $\mathrm{H}$ atoms must donate electrons to the skeletal bonds. The sketch is given in Fig. 4.

The value of $\mathrm{k}_{2}$ is obtained from $\mathrm{E}_{2}=$ $2 \times 8+6 \times 2=28$, and $\mathrm{V}=2 \times 3+6 \times 1=12$. This gives a calculated $k_{2}=1 / 2(28-12)=8$. This corresponds to the total linkages of 8 as seen from Fig. 4 .

The $k_{2}$ value gives all the total linkages including the bridges. Each bridge taken as equivalent to two linkages. It is quite clear from the sketch in Fig.
4 that there is resemblance to that of $\mathrm{C}_{2} \mathrm{H}_{4}$ shown in Fig. 3. Thus, a $(\mathrm{BH})$ fragment can regarded as equivalent to a $(\mathrm{C})$ atom. That is, $\mathrm{BH}=\mathrm{C}$ as these are isoelectronic. This also means that we can regard $\mathrm{BH}_{3}$ to be equivalent to $(\mathrm{BH}) \mathrm{H}_{2}=\mathrm{CH}_{2}$. Hence, $2 \mathrm{CH}_{2}$ $=2(\mathrm{BH}) \mathrm{H}_{2}$. This makes visual sense for sketches of $\mathrm{C}_{2} \mathrm{H}_{4}$ in Fig. 3 and $\mathrm{B}_{2} \mathrm{H}_{6}$ in Fig. 4.

Deriving the shapes of boranes using $k_{1}$ and $k_{2}$ values

$$
\mathrm{B}_{2} \mathrm{H}_{7}^{\text {Ë\#- }} \text { ion }\left(\mathrm{k}_{1}=1, \mathrm{k}_{2}=8\right)
$$

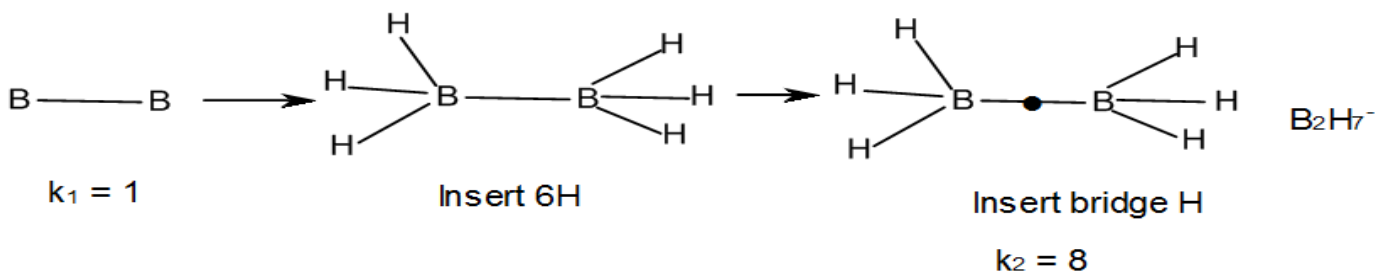

Fig. 5: Structure of $\mathrm{B}_{2} \mathrm{H}_{7}$

The $\mathrm{k}$ values imply that the two boron atoms are connected by a bridge(2 linkages) and each $B$ atom will have three terminal hydrogens( Fig. 5).

The sketch of $\mathrm{B}_{2} \mathrm{H}_{7}$ E\#- $^{-}$is isoelectronic to that of $\mathrm{C}_{2} \mathrm{H}_{6}$ which has a similar resemblance.

$$
\mathrm{B}_{3} \mathrm{H}_{8}^{\text {Ë\# }} \text { ion }\left(\mathrm{k}_{1}=3, \mathrm{k}_{2}=11\right)
$$

The value of $\mathrm{k}_{1}=3$ for $\mathrm{B}_{3} \mathrm{H}_{8} \mathrm{E \#}^{\mathrm{E}}$ ion implies that the three boron atoms are linked by three bonds to form a trigonal planar geometry. In order for each $B$ atom to obey the octet rule, two terminal linkages

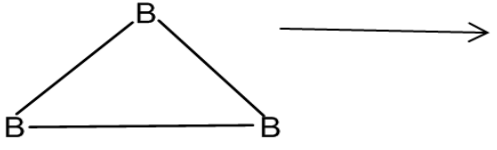

$\mathrm{k}_{1}=3$

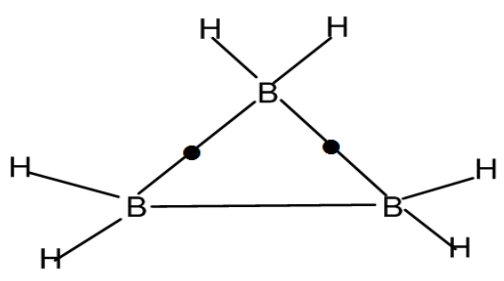

$\mathrm{k}_{2}=11$

Fig. 6: The structure of $\mathrm{B}_{3} \mathrm{H}_{8}$

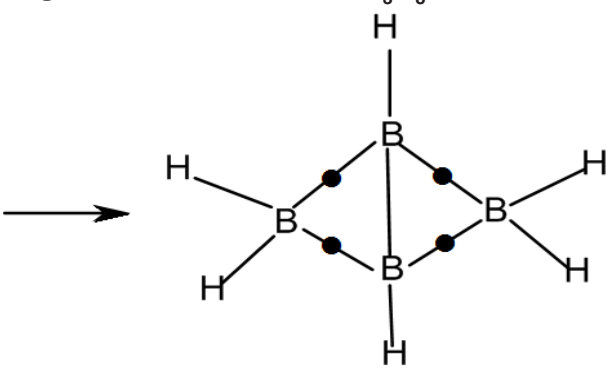
$\mathrm{k}_{1}=5, \mathrm{k}_{2}=15$

Fig. 7: Structure of $\mathrm{B}_{4} \mathrm{H}_{10}$ 


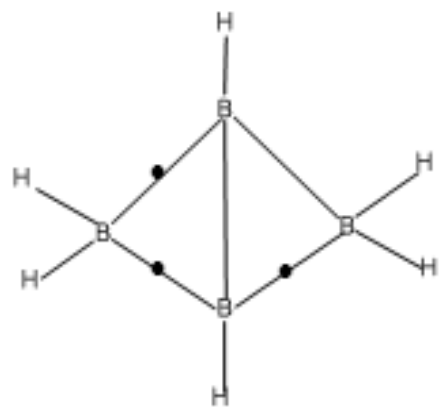

Fig. 8. $\mathrm{B}_{4} \mathrm{H}_{6}$

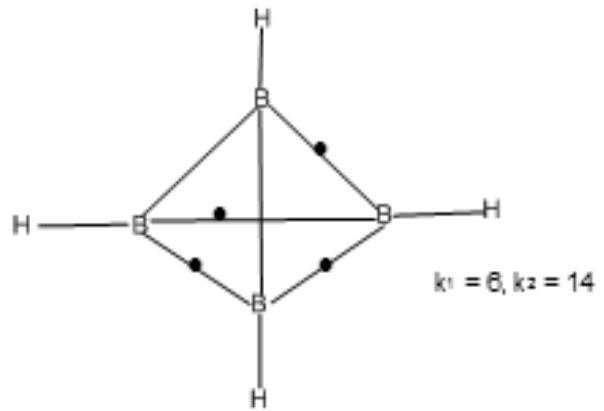

Fig. 9. $\mathrm{B}+\mathrm{Ha}^{-}$

$\left.\mathrm{B}_{4} \mathrm{H}_{7}\right\urcorner-$ cluster $\left.\left(\mathrm{k}_{1}=6, \mathrm{k}_{2}=13\right) \quad \mathrm{B}_{4} \mathrm{H}_{4}\right\urcorner 2-$ cluster $\left(\mathrm{k}_{1}=7, \mathrm{k}_{2}=11\right)$

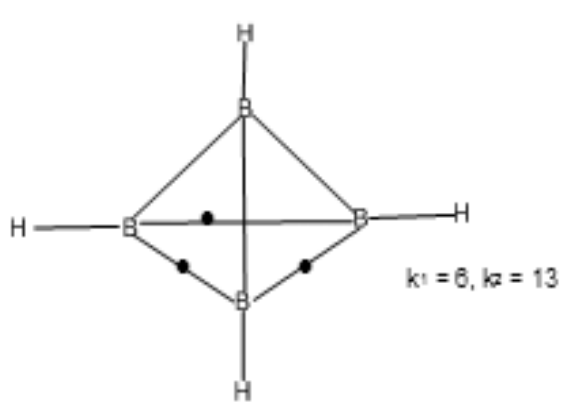

Fig. 10. B $+\mathrm{Hr}^{-}$

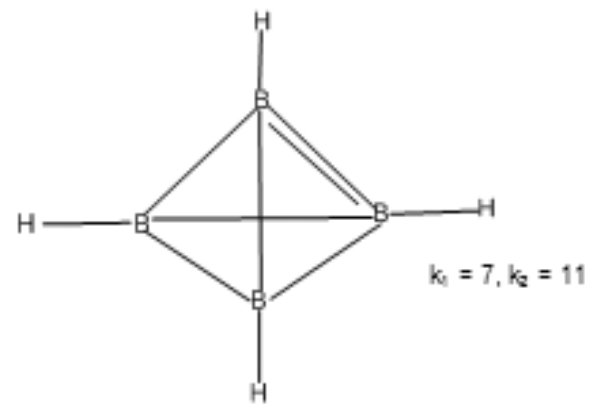

Fig. 11. $\mathrm{B}_{4} \mathrm{H}_{4}^{2-}$

$\left.\mathrm{B}_{4} \mathrm{H}_{4}\right\urcorner 4$ - cluster $\left(\mathrm{k}_{1}=6, \mathrm{~K}_{2}=13\right)$

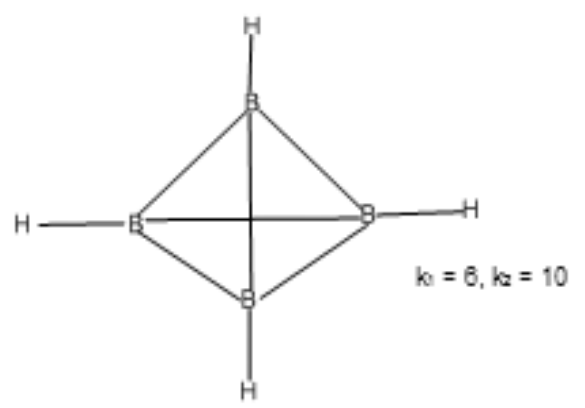

Fiq. 12. $\mathrm{B}_{4} \mathrm{H}_{4}^{2-}$

$B_{5} H_{9}$ molecule $\left(k_{1}=8, k_{2}=17\right)$ 
have to be introduced. This needs $6 \mathrm{~B}-\mathrm{H}$ terminal bonds leaving 2 hydrogen atoms to be inserted into bridges. The final geometry is shown in Fig. 6.
After insertion of the two bridges, the total number of linkages corresponds to $\mathrm{k}_{2}=11$. $\mathrm{B}_{4} \mathrm{H}_{10}$ molecule $\left(\mathrm{k}_{1}=5, \mathrm{k}_{2}=15\right)$

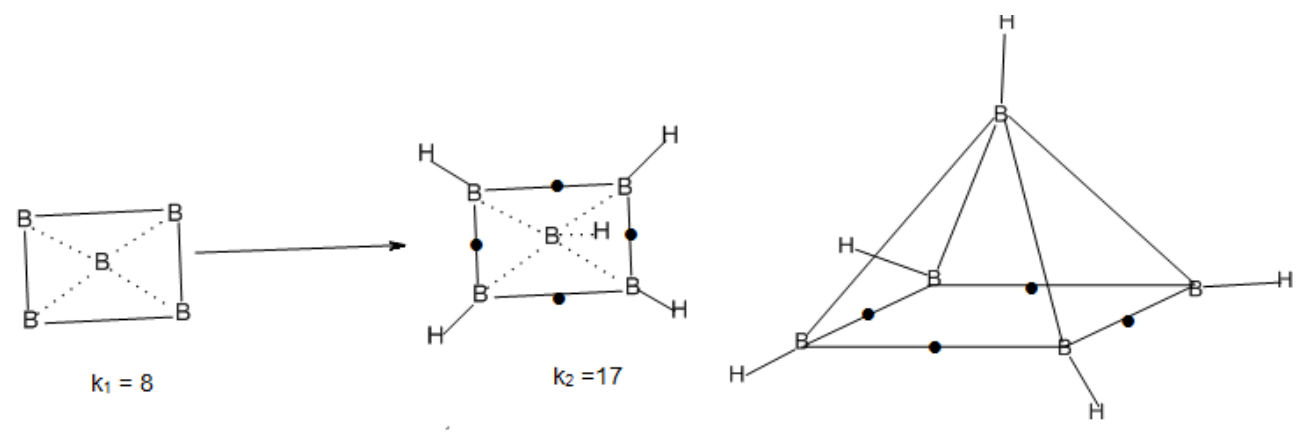

Fig. 8: Structure of $\mathrm{B}_{5} \mathrm{H}_{9}$

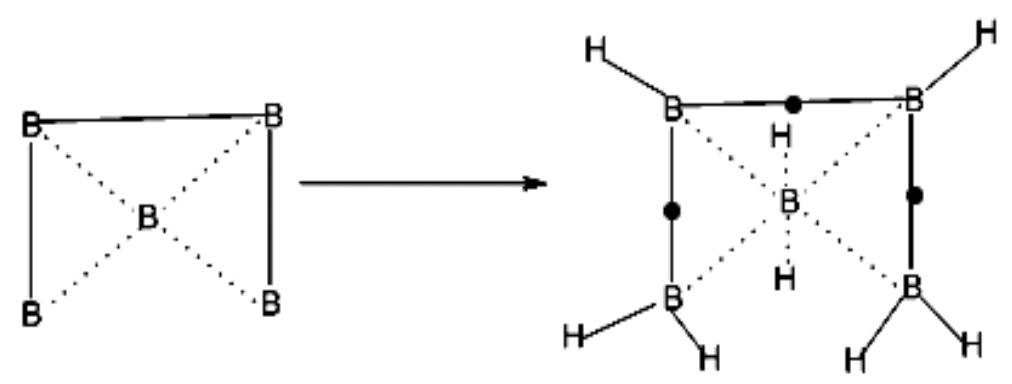

$k 1=7$

$\mathrm{C}_{\text {s symmetry }}$

$$
k_{2}=18
$$

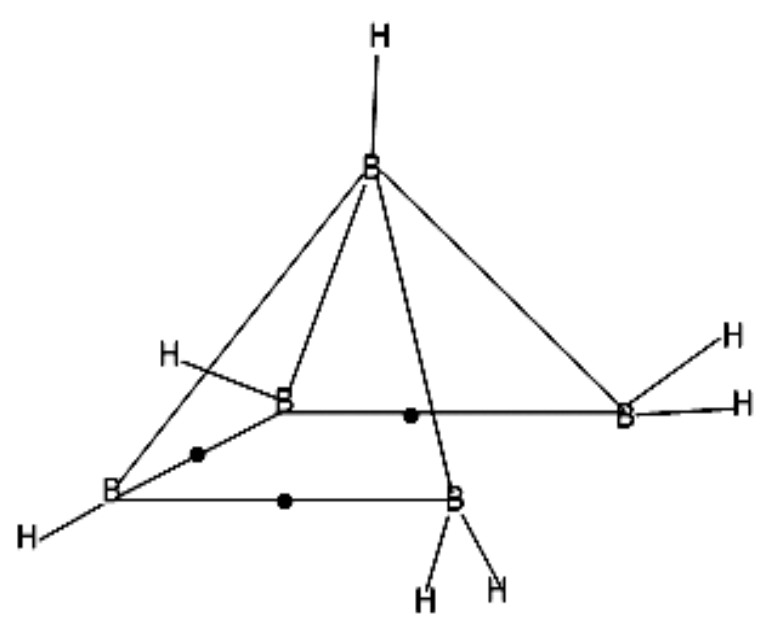

Shape of a hut

Fig. 9: Structures of $\mathrm{B}_{5} \mathrm{H}_{11}, \mathrm{~B}_{5} \mathrm{H}_{8}{ }^{\ddot{E}}, \mathrm{~B}_{5} \mathrm{H}_{12}$ Ë\# Clusters 
$\left.\mathrm{B}_{5} \mathrm{H}_{8}\right\urcorner-$ Cluster

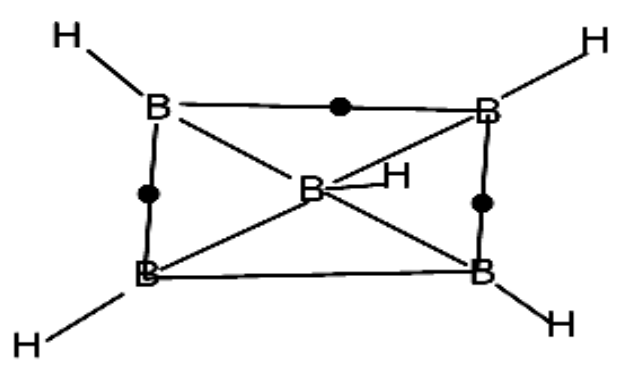

$\left.\mathrm{B}_{5} \mathrm{H}_{8}\right\urcorner-, \mathrm{k}_{1}=8, \mathrm{k}_{2}=16$

One possible geometry consistent with these k-values is shown in fig...

Influence of varying of $\mathrm{H}$ atoms and Charge on the geometry of $B_{n}$ Fragment

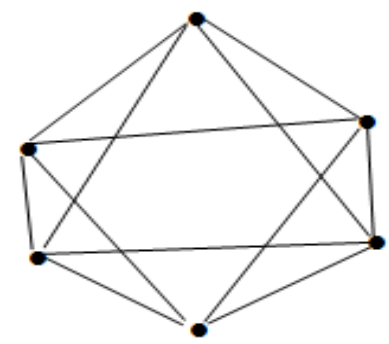

$\mathrm{k}_{1}=11 ;$ octahedral symmetry, $\mathrm{O}_{\mathrm{h}} \quad \mathrm{k}_{2}=17$
$\left.\mathrm{B}_{5} \mathrm{H}_{12}\right\urcorner-$ Cluster

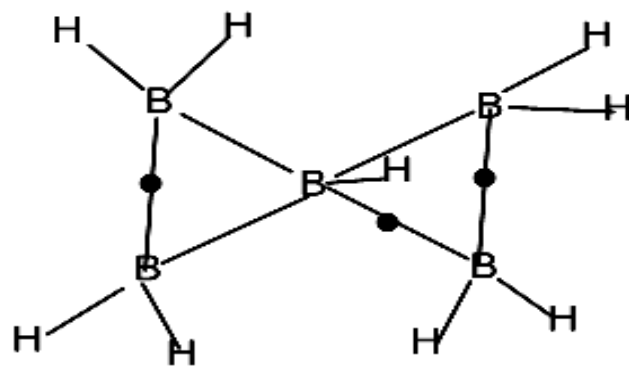

$\left.\mathrm{B}_{5} \mathrm{H}_{12}\right\urcorner-{ }_{m x} \mathrm{k}_{1}=6, \mathrm{k}_{2}=18$

The variation of the number of $\mathrm{H}$ atoms and the charge on the $B_{n}$ fragment of the cluster has an influence on the cluster geometry. This is illustrated by the variation in the structure of $B_{4}$ fragment in the clusters shown in the following Figs 8-

Fig. 10: Structure of $\mathrm{B}_{6} \mathrm{H}_{6}{ }^{2-}$

\section{$B_{5} \mathrm{H}_{9}$ molecule $\left(k_{1}=8, k_{2}=17\right)$}

The hydride $\mathrm{B}_{5} \mathrm{H}_{11}\left(\mathrm{k}_{1}=8\right)$ implies a square pyramid skeleton $\left(\mathrm{C}_{4 \mathrm{v}}\right.$ symmetry). When bridges and terminal bonds are included, the total linkages become 17. The plausible shapes are shown in Fig. 8.

\section{$\mathrm{B}_{5} \mathrm{H}_{11}$ borohydride $\left(\mathrm{k}_{1}=7, \mathrm{k}_{2}=18\right)$}

The skeletal geometry of $\mathrm{B}_{5} \mathrm{H}_{11}\left(\mathrm{k}_{1}=7\right)$ may be considered a derivative of that of $\mathrm{B}_{5} \mathrm{H}_{11}\left(\mathrm{k}_{1}=8\right)$ with one base side removed. To move from $\mathrm{k}_{1}=7$ to $k_{2}=18$ ) bridges and terminal bonds have to be included. This is shown in Fig. 9.

Shape of a hut
$\mathrm{B}_{6} \mathrm{H}_{6}{ }^{\ddot{E} \# 2^{-}}$cluster ion $\left(\mathrm{k}_{1}=11, \mathrm{k}_{2}=17=11+6\right)$

$\mathrm{B}_{6} \mathrm{H}_{6}$ Ë\#2- $^{-}$cluster ion has $\mathrm{k}_{1}$ value of 11 and $k_{2}$ value of 17 . The difference between $k_{2}$ and $k_{1}$ is 6 . This represents the six $\mathrm{B}-\mathrm{H}$ terminal bonds for

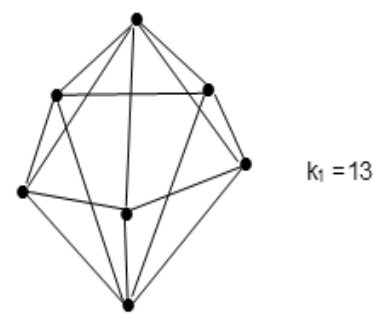

Skeletal geometry of $\mathrm{B}_{7} \mathrm{H}_{7}{ }^{2-}$ cluster

Fig. 10: Structure of $\mathrm{B}_{6} \mathrm{H}_{6}{ }^{2-}$ 
Table 1: The $k_{1}$ and $k_{2}$ values for Selected Closo Boranes $\mathrm{B}_{\mathrm{n}} \mathrm{H}_{\mathrm{n}}{ }^{\ddot{E} \# 2-}$

\begin{tabular}{lcc}
\hline $\mathrm{n}$ & $\mathrm{k}_{1}$ & $\mathrm{k}_{2}$ \\
2 & 3 & 5 \\
3 & 5 & 8 \\
4 & 7 & 11 \\
5 & 9 & 14 \\
6 & 11 & 17 \\
7 & 13 & 20 \\
8 & 15 & 23 \\
9 & 17 & 26 \\
10 & 19 & 29 \\
11 & 21 & 32 \\
12 & 23 & 35 \\
13 & 25 & 38 \\
14 & 27 & 41 \\
15 & 29 & 44 \\
16 & 31 & 47 \\
17 & 33 & 50 \\
18 & 35 & 53 \\
19 & 37 & 56 \\
20 & 39 & 59 \\
\hline
\end{tabular}

Table 2: The $\mathbf{k}$ values of Selected Boranes

\begin{tabular}{|c|c|c|c|c|c|}
\hline Molecule/lon & $E_{1}$ & $\mathbf{V}$ & $k_{1}=1 / 2\left(E_{1}-V\right)$ & $E_{2}$ & $\begin{array}{c}k_{2}=1 / 2\left(E_{2}-V\right) \\
k_{2}^{*}=k_{1}+n\end{array}$ \\
\hline 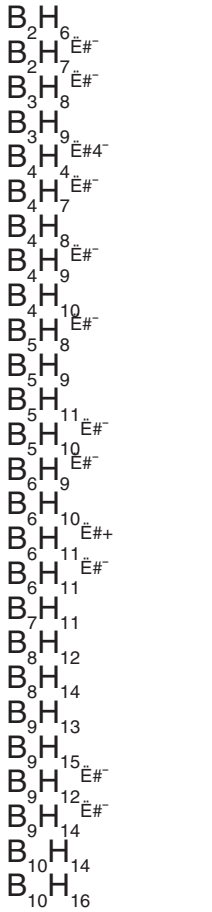 & $\begin{array}{l}16 \\
16 \\
24 \\
24 \\
32 \\
32 \\
32 \\
32 \\
32 \\
40 \\
40 \\
40 \\
40 \\
48 \\
48 \\
48 \\
48 \\
56 \\
64 \\
64 \\
72 \\
72 \\
72 \\
72 \\
80 \\
80\end{array}$ & $\begin{array}{l}12 \\
14 \\
18 \\
18 \\
20 \\
20 \\
20 \\
22 \\
22 \\
24 \\
24 \\
26 \\
62 \\
28 \\
28 \\
28 \\
30 \\
32 \\
36 \\
38 \\
40 \\
42 \\
40 \\
42 \\
44 \\
46\end{array}$ & $\begin{array}{c}2 \\
1 \\
3 \\
3 \\
6 \\
6 \\
6 \\
5 \\
5 \\
8 \\
8 \\
7 \\
7 \\
10 \\
10 \\
10 \\
9 \\
12 \\
14 \\
13 \\
16 \\
15 \\
16 \\
15 \\
18 \\
17\end{array}$ & $\begin{array}{c}28 \\
30 \\
40 \\
42 \\
40 \\
46 \\
48 \\
50 \\
52 \\
56 \\
58 \\
62 \\
60 \\
66 \\
68 \\
70 \\
70 \\
78 \\
88 \\
92 \\
98 \\
102 \\
96 \\
94 \\
108 \\
112\end{array}$ & $\begin{array}{c}8 \\
8 \\
8 \\
11 \\
12 \\
10 \\
13 \\
14 \\
14 \\
15 \\
16 \\
17 \\
18 \\
17 \\
19 \\
20 \\
21 \\
20 \\
23 \\
26 \\
27 \\
29 \\
30 \\
28 \\
26 \\
32 \\
33\end{array}$ \\
\hline
\end{tabular}

${ }^{*} \mathrm{n}=$ number of $\mathrm{H}$ atoms on cluster. 
Table 3: The $k$ values of Closo systems from $n=2$ to 12 and possible Shapes

\begin{tabular}{|c|c|c|c|c|c|c|c|}
\hline $\begin{array}{l}\mathrm{B}_{\mathrm{n}} \mathrm{H}_{\mathrm{n}}^{\mathrm{E} \# 2^{-}} \text {Ion } \\
\text { Closo system }\end{array}$ & $E_{1}$ & $\mathbf{v}$ & $\begin{array}{l}k_{1}=1 / 2 \\
\left(E_{1}-V\right)\end{array}$ & $E_{2}$ & $\begin{array}{l}k_{2}=1 / 2 \\
\left(E_{2}-V\right)\end{array}$ & $\begin{array}{c}N=1 / 2\left(k_{1}+1\right) \\
\text { Vertices }\end{array}$ & Possible geometry \\
\hline 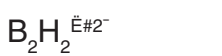 & 16 & 10 & 3 & 20 & 5 & 2 & \\
\hline $\mathrm{B}_{3}^{2} \mathrm{H}_{3}^{2} \mathrm{EH}^{-}$ & 24 & 14 & 5 & 30 & 8 & 3 & \\
\hline $\mathrm{B}_{4} \mathrm{H}_{4}^{3} \# 2^{-2}$ & 32 & 18 & 7 & 40 & 11 & 4 & \\
\hline $\mathrm{B}_{5} \mathrm{H}_{5}^{4} \mathrm{EH}^{-}$ & 40 & 22 & 9 & 50 & 14 & 5 & Trigonal bipyramid \\
\hline $\mathrm{B}_{6} \mathrm{H}_{6}^{5} \mathrm{EH}^{-}$ & 48 & 26 & 11 & 60 & 17 & 6 & Octahedral \\
\hline $\mathrm{B}_{7} \mathrm{H}_{7}^{6 . \# 2^{-}}$ & 56 & 30 & 13 & 70 & 20 & 7 & Pentagonal bipyramid \\
\hline $\mathrm{B}_{8} \mathrm{H}_{8}^{\mathrm{E \#} 2^{-}}$ & 64 & 34 & 15 & 80 & 23 & 8 & Dodecahedron \\
\hline $\mathrm{B}_{9}^{8} \mathrm{H}_{9}^{\mathrm{E} \# 2^{-}}$ & 72 & 38 & 17 & 90 & 26 & 9 & Tricapped trigonal prism \\
\hline $\mathrm{B}_{10} \mathrm{H}_{10}{ }^{\mathrm{E} \# 2^{-}}$ & 80 & 42 & 19 & 100 & 29 & 10 & $\begin{array}{l}\text { Bicapped square } \\
\text { antiprism }\end{array}$ \\
\hline $\mathrm{B}_{11} \mathrm{H}_{11} \mathrm{E}^{\mathrm{E}} 2^{-}$ & 88 & 46 & 21 & 110 & 32 & 11 & Octadecahedron \\
\hline $\mathrm{B}_{12} \mathrm{H}_{12}{ }_{\mathrm{E} \# 2^{-}}$ & 96 & 50 & 23 & 120 & 35 & 12 & Icosahedron \\
\hline
\end{tabular}

this closo system. The $\mathrm{k}$ value of 11 for six skeletal atoms is characteristic of an octahedral skeletal symmetry $\left(\mathrm{O}_{\mathrm{h}}\right)$ (Fig. 10.). It is interesting to note that whereas the $\mathrm{k}_{1}$ values of $\mathrm{B}_{4} \mathrm{H}_{4}{ }^{\mathrm{E} \# 2^{-}}\left(\mathrm{k}_{1}=6\right)$ and $\mathrm{B}_{5} \mathrm{H}_{5} \mathrm{E}^{\mathrm{E}} 2^{-}$ $\left(\mathrm{k}_{1}=9\right)$ correspond to the number of total skeletal linkages, whereas in $\mathrm{B}_{6} \mathrm{H}_{6}{ }^{\text {Ë\#2- }}\left(\mathrm{k}_{1}=11\right)$ octahedral skeletal symmetry, this is not the case. The $\mathrm{k}_{2}=17$ represents $k_{1}=11$ for skeletal symmetry plus 6 for hydrogen bond linkages.

\section{$\mathrm{B}_{7} \mathrm{H}_{7}{ }^{\ddot{E} \# 2^{-}}$cluster ion}

The $\mathrm{B}_{7} \mathrm{H}_{7}{ }^{\text {E\#2- }}$ cluster ion has a characteristic $k_{1}$ value of 13 and $k_{2}$ of 20 . It is found to adopt a pentagonal bipyramid skeletal geometry $\left(D_{5 h}\right)$. This is shown in Fig. 11.

\section{Closo Boranes}

The closoboranes have characteristic $k_{1}$ values which have number series that begins with $\mathrm{k}_{1}=3$ for $\mathrm{B}_{2} \mathrm{H}_{2}{ }^{\text {E\#2 }}, \mathrm{B}_{3} \mathrm{H}_{3}$ Ё2- $^{-}\left(\mathrm{k}_{1}=5\right), \mathrm{B}_{4} \mathrm{H}_{4}{ }^{\text {Е\#2 }}\left(\mathrm{k}_{1}\right.$ $=7), \mathrm{B}_{5} \mathrm{H}_{5}$ Е\#2 $^{-}\left(\mathrm{k}_{1}=9\right), \mathrm{B}_{6} \mathrm{H}_{6}{ }^{\text {E\#2 }}\left(\mathrm{k}_{1}=11\right), \mathrm{B}_{7} \mathrm{H}_{7}$ Ё\#2 $^{-}\left(\mathrm{k}_{1}\right.$

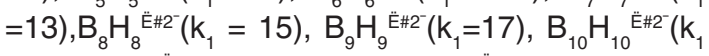

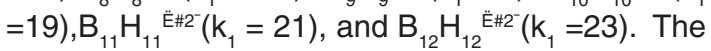
$k_{1}$ values form a series of odd numbers for the closo series.

\section{The conjucto clusters}

The empirical formula could be extended to the interpretation of geometries of large clusters. Take the example of $\mathrm{B}_{8} \mathrm{H}_{18}=\left(\mathrm{B}_{4} \mathrm{H}_{9}\right)_{2}$ cluster. This cluster has $k_{1}=11$. This can be split into $5+1+5$. A plausible isomer consistent with this is given below.

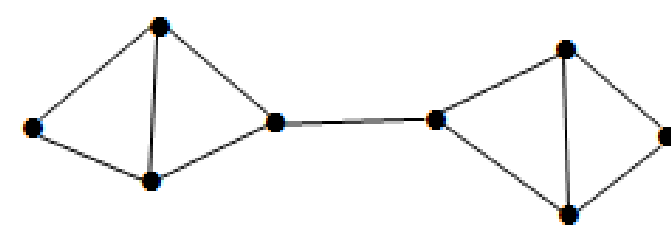

$\mathrm{B}_{8} \mathrm{H}_{18}=\left(\mathrm{B}_{4} \mathrm{H}_{9}\right)_{2}$ c luster

$\mathrm{k}_{1}=11=5+1+5$

$B_{10} H_{16}\left(k_{1}=17\right)$.

This can be separated into $8+1+8$ units. The $k_{1}=8$ is a square pyramid of $B_{5} H_{8}$. This means that two fragments of $\mathrm{B}_{5} \mathrm{H}_{8}$ are linked up by a single bond. The shape of $\mathrm{B}_{10} \mathrm{H}_{16}$ is shown below. This is an example of a bridged fragments or skeletal units of boranes.

\section{Closo Series}

The closoboranes are given by the formula $\mathrm{B}_{n} \mathrm{H}_{n}$ Ë\#2- The $\mathrm{k}_{1}$ and $\mathrm{k}_{2}$ values of the closo series are given in Table 1.

It is quite clear from Table 1 that the $\mathrm{k}$ values form arithmetical series. The series for $k_{1}$ values follow the pattern given by $T_{1}=a_{n}+(n-1) d ; a_{1}=3$, $d$ $=2$, and $T_{1}=n^{\text {th }}$ value of $k_{1}$. On the other hand for $k_{2}$ series is given by $T_{2}=a_{n}+(n-1) d ; a_{1}=5$ and $d=3$ and $T_{2}=n^{\text {th }}$ value of $k_{2}$. 


\section{CONCLUSION}

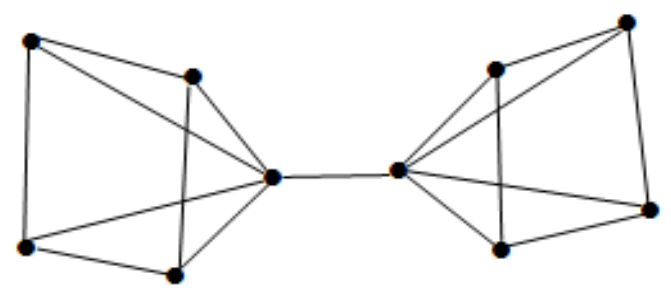

$\mathrm{k}_{1}=17 ; \mathrm{B}_{10} \mathrm{H}_{16}$ skeletal linkages

The $k_{1}$ and $k_{2}$ values of selected neutral and ionic boranes from $B_{2}$ to $B_{12}$ boron-based systems are given in Table 2. Table 3 gives the linkage of $k_{1}$ and $k_{2}$ values of the closo series to vertices and shapes of known closo borane ions such as $\mathrm{B}_{5} \mathrm{H}_{5}{ }^{\mathrm{E} \# 2^{2}}$, $\mathrm{B}_{5} \mathrm{H}_{5}^{\stackrel{\mathrm{E}}{\mathrm{E}} 2^{-}}$, andB $\mathrm{B}_{7} \mathrm{H}_{7}^{\mathrm{E} \# 2^{-}}$.
The $k$ values of simple neutral and ionic boranes can be used as guide to explain the shapes and symmetries of the same. Furthermore, they can act as an identity for characteristic shapes of molecules and ions especially the closo systems. For instance, $k_{1}=11$ is characteristic of an octahedral geometry as in the case of $\mathrm{B}_{6} \mathrm{H}_{6} \mathrm{EH}^{-}$or $\mathrm{k}_{1}=13$ for pentagonal bipyramid for $\mathrm{B}_{7} \mathrm{H}_{7} \mathrm{E}^{\mathrm{E}} 2^{-}$. The empirical formula $k=1 / 2(E-V)$ is versatile as it can be utilized to sketch Lewis shapes of simple ions and molecules as well as clusters of simples molecules and ions of the main group elements. It can be extended to explain the shapes of simple transition metal clusters containing carbonyl ligands. The empirical formula is also applicable to carboranes since they are related to boranes. It is hoped that the empirical formula will find some applications in more complex molecular systems where the 2, 8 and 18 electron rules are obeyed.

\section{REFERENCES}

1. Stock, A., Hydrides of Boron and Silicon, Cornell University Press. Ithaca, New York, (1933).

2. Fox, M. A.; Wade, A. Pure and Appl. Chem., 2003, 75(9), 1315-1323 and references therein

3. http://en.wikipedia.org/wiki ; downloaded 2007-2014.

4. Zhang, X. B.; Hans, S.; Yan, J. M.; Chandra, M.; Shioyana, H.; Yasuda,K.; Kariyama, N.;Kobayashi,T.; Xu,Q. Journal of Power Sources, 2007, 168, 167-171.

5. Hawthorne, M. F.;Varadarajan, A.; Knobler, C. R.; Chakrarti, S.;Paxton, R. J; Beatty, B. G.; Curtis, F. L. J. Am. Chem. Soc.1990, 112(13), 5365-5366

6. Hawthorne, M. F., and Maderna, A. Chem. Rev. 1999, 99, 3421-3434.

7. Sneddon, L. G. Pure and Appl. Chem.1987,
59(7), 837-846.

8. Hall, C.; Thakaran, P.; Hallock, J.; Cleveland,C.; Jefferson, M. Nature 2003,426, 318-322.

9. Wade, A. Adv. Inorg. Chem. Radiochem. 1976, 18, 1-66.

10. Mingos, D. M. P. Acc. Chem. Res. 1984, 17(9), 311-319.

11. Shore, S. G. Pure and Appl. Chem. 1977, 49(6), 717-732.

12. McGlinchey, M. J.; Hopf, H. Beilstein J. Org. Chem.2011, 7. 222-233.

13. Jemmis, E. D.; Balakrishnarajan, M. M.; Pancharatna, P. D. J. Am., Chem. Soc.2001, 123(18), 4313-4323.

14. Welch, A., J. Chem. Comm. 2013, 49, 36153616

15. Kiremire, E. M. R. Oriental J. Chem. 2007, 32(2), 809-812.

16. Kiremire, E. M. R.; Kiremire, E. B. B. Materials Science Research India 2007, 4(1), 09-18. 